\title{
Response to Letter to Editor by Dr. Aminnejad et al.
}

\author{
Reyhaneh Shahrokhirad ${ }^{1}$, Soudabeh Haddadi ${ }^{1}$ and Malek Moien Ansar ${ }^{2,3,{ }^{*}}$ \\ ${ }^{1}$ Anesthesiology Research Center, Department of Anesthesiology, Al-Zahral Hospital, Guilan University of Medical Sciences, Rasht , Iran \\ ${ }^{2}$ Neuroscience Research Center, Department of Biochemistry, Poursina Hospital, School of Medicine, Guilan University of Medical Sciences, Rasht, Iran \\ ${ }^{3}$ Department of Biochemistry, School of Medicine, Guilan University of Medical Sciences, Rasht, Iran \\ "Corresponding author: Department of Biochemistry, School of Medicine, Guilan University of Medical Sciences, Rasht, Iran. Email: ansar_moien@yahoo.com
}

Received 2019 August 28; Accepted 2019 October 04.

See the letter "Efficacy of Preoperative Administration of Acetaminophen and Melatonin on Retrobulbar Block Associated Pain in Cataract Surgery: A Letter to Editor".

\section{Dear Editor,}

We would like to thank Dr. Aminnejad and Dr. Sabouri for their interest in our article and expressing their concern regarding the use of melatonin in cataract surgery (1).

The primary concern noted was that the use of melatonin as a preemptive analgesic drug may delay recovery and discharge in short-time surgeries. Because of returning to basal concentrations in 4 to 8 hours (2), they believed that melatonin is not a short-acting drug. The drug elimination half-life is not an appropriate criterion for evaluating the efficacy of a drug. Melatonin does not last longer than fentanyl (a short-acting opioid agonist) because melatonin elimination half-life is 1.8-2.1 hours (3) but that of fentanyl is $8-10$ hours (4). The short-acting effect of single-dose fentanyl administration is not due to elimination half-life, but to its rapid redistribution (5). Melatonin like fentanyl acts as a short-acting drug because it crosses easily the blood-brain barrier by its amphipathic nature $(6,7)$. Oral administration of melatonin at pharmacological doses could not impair the motor performance, memory, and visual sensitivity and therefore, it is a drug with short-acting sedative-like properties (8). Also, from data not presented in our recently published paper (9), we found no significant difference between melatonin and placebo groups in the orientation score (both in terms of place and time) before entering the operating room, after surgery, and during recovery time.

Hence, we concluded that due to its short-acting feature, melatonin can be considered for short- time surgeries.

\section{Acknowledgments}

We dedicate our special thanks to Mostafa Haghiri (MA in English Linguistics) for editing the manuscript.

\section{Footnotes}

Authors' Contribution: Reyhaneh Shahrokhirad and Soudabeh Haddadi helped in drafting the manuscript.
Malek Moien Ansar was involved in revising the manuscript.

Conflict of Interests: We declare no conflict of interests. Funding/Support: No funding to declare.

\section{References}

1. Aminnejad R, Sabouri SM. Efficacy of preoperative administration of acetaminophen and melatonin on retrobulbar block associated pain in cataract surgery: A letter to editor. Anesth Pain Med. 2019;9(1). e84957. doi: 10.5812/aapm.84957. [PubMed: 30881908]. [PubMed Central: PMC6412315].

2. Tordjman S, Chokron S, Delorme R, Charrier A, Bellissant E, Jaafari N, et al. Melatonin: Pharmacology, functions and therapeutic benefits. Curr Neuropharmacol. 2017;15(3):434-43. doi: 10.2174/1570159X14666161228122115. [PubMed: 28503116]. [PubMed Central: PMC5405617].

3. Gooneratne NS, Edwards AY, Zhou C, Cuellar N, Grandner MA, Barrett JS. Melatonin pharmacokinetics following two different oral surgesustained release doses in older adults. J Pineal Res. 2012;52(4):437-45. doi: 10.1111/j.1600-079X.2011.00958.x. [PubMed: 22348451]. [PubMed Central: PMC3682489].

4. Kharasch ED. Opioid half-lives and hemlines: The long and short of fashion. Anesthesiology. 2015;122(5):969-70. doi: 10.1097/ALN.0000000000000634. [PubMed: 25768861]. [PubMed Central: PMC4439340].

5. Peng PW, Sandler AN. A review of the use of fentanyl analgesia in the management of acute pain in adults. Anesthesiology. 1999;90(2):57699. doi: 10.1097/00000542-199902000-00034. [PubMed: 9952166].

6. Salehi B, Sharopov F, Fokou PVT, Kobylinska A, Jonge L, Tadio $\mathrm{K}$, et al. Melatonin in medicinal and food plants: Occurrence, bioavailability, and health potential for humans. Cells. 2019;8(7). doi: 10.3390/cells8070681. [PubMed: 31284489]. [PubMed Central: PMC6678868].

7. Hug C, Murphy MR, Rigel EP, Olson WA. Pharmacokinetics of morphine injected intravenously into the anesthetized dog. Anesthesiology. 1981;54(1):38-47. doi: 10.1097/00000542-198101000-00008. [PubMed: 7457981].

8. Lieberman HR, Waldhauser F, Garfield G, Lynch HJ, Wurtman RJ. Effects of melatonin on human mood and performance. Brain Res. 1984;323(2):201-7. doi: 10.1016/0006-8993(84)90290-7. [PubMed: 6525511].

9. Haddadi S, Shahrokhirad R, Ansar MM, Marzban S, Akbari M, Parvizi A. Efficacy of preoperative administration of acetaminophen and melatonin on retrobulbar block associated pain in cataract surgery. Anesth Pain Med. 2018;8(5). e61041. doi: 10.5812/aapm.61041. [PubMed: 30533388]. [PubMed Central: PMC6240829]. 